\title{
Google Trends as a Method to Predict New COVID-19 Cases and Socio-Psychological Consequences of the Pandemic
}

\begin{abstract}
By Tado Juric ${ }^{*}$
Understanding how people react to the COVID-19 crisis, and what the consequences are of the COVID-19 pandemic is key to enable public health and other agencies to develop optimal intervention strategies. Because the timely identification of new cases of infection has proven to be the key to timely respond to the spread of infection within a particular region, we have developed a method that can detect and predict the emergence of new cases of COVID-19 at an early stage. Further, this method can give useful insights into a family's life during the pandemic and give the prediction of birth rates. The basic methodological concept of our approach is to monitor the digital trace of language searches with the Google Trends analytical tool (GT). We divided the keyword frequency for selected words giving us a search frequency index and then compared searches with official statistics to prove the significations of results. 1) Google Trends tools are suitable for predicting the emergence of new COVID-19 cases in Croatia. The data collected by this method correlate with official data. In Croatia search activities using GT for terms such as "PCR +COVID", and symptoms "cough + corona", "pneumonia + corona"; "muscle pain + corona" correlate strongly with officially reported cases of the disease. 2) The method also shows effects on family life, increase in stress, and domestic violence. 3) Birth rate in 2021 will be just $87 \%$ of what it would be "a normal year" in Croatia. 4) This tool can give useful insights into domestic violence. Unquestionably, there are still significant open methodological issues and the questionable integrity of the data obtained using this source. The fact is also a problem that GT does not provide data on which population was sampled or how it was structured. Although these open-ended issues pose serious challenges for making clear estimates, statistics offer a range of tools available to deal with imperfect data as well as to develop controls that take data quality into account. All these insights show that GT has the potential to capture attitudes in the broad spectrum of family life themes. The benefit of this method is reliable estimates that can enable public health officials to prepare and better respond to the possible return of a pandemic in certain parts of the country and the need for responses to protect family well-being.
\end{abstract}

Keywords: Google trends, COVID-19, birth rates, domestic violence, Croatia, predicting demographic trends, family

\footnotetext{
*Assistant Professor, Catholic University of Croatia, Croatia.
} 


\section{Introduction}

In the absence of medical treatment and vaccination, the mitigation and containment of the ongoing COVID-19 pandemic rely on behavioural changes. Timely data on attitudes and behaviours are thus necessary to develop optimal intervention strategies and to assess the consequences of the pandemic (Perotta et al. 2020). A key problem is a lack of data to assess people's and thus family's behaviour and reactions to epidemics. Decision-making and the evaluation of nonpharmaceutical interventions require specific, reliable, and timely data not only about infections but also about human and family behaviour. We seek to narrow this data gap by monitoring individual and family behaviours in response to the COVID-19 pandemic in Croatia. We used Croatia as a case study because the country is an extremely interesting case of studying the consequences of the pandemic on family life. After all, it was the first EU member state, to experience two strong earthquakes (March and December 2020; SSOC 2020a, 2020b), in addition to the pandemic. This further affected the spread of the pandemic and increased risk factors in families and which increased death rates. Furthermore, there are no studies of this type (digital demography) in Croatia and the wider region of Southeast Europe. When it comes to the use of the Internet, Croatia is generally comparable to the EU average so the results of this study can be compared with other EU countries. Here it is important to briefly mention that Google search engine is the most popular search engine in Croatia, preferred by 97.21\% of users (StatCounter 2020), similar to EU level (92.92\%; Jurić 2021b, d).

The COVID-19 outbreak and lockdown accelerated the adoption of digital solutions at an unprecedented pace, creating unforeseen opportunities for scaling up alternative approaches to social science (Hantrais and Lenihan 2021). We will show that GT has the potential to capture attitudes in the broad spectrum of family life themes. These insights can be very useful to understand and predict some behaviours in the field of public health and for monitoring families but also for predicting new COVID-19 cases in a specific area. The basic methodological concept of our approach is to monitor the digital trace of language searches with the Google Trends analytical tool ${ }^{1}$.

After briefly showing the results of relevant studies in digital demography in the next section, in section 3 we will give a brief overview of the spread of coronavirus in Croatia. This overview is important for the comparison of results that we received with GT with official results. The next section shows how this method can predict the increase in new cases of infection in a particular region promptly and enable the public offices to act accordingly with additional measures. Then, we show how GT can be used as a method to predict the socio-psychological impact of the pandemic in Croatia on families and growth indicators of domestic violence during the pandemic in Croatia. We end the article with Google Trends indicators about the consequences of the COVID-19 pandemic on the fertility rate in Croatia in the year 2021.

\footnotetext{
${ }^{1}$ trends.google.com.
} 
Although previous research in this area has shown the feasibility of using digital data for demography (Zagheni et al. 2017, Jurić 2021b, d), it is unquestionable that there are still significant open methodological issues and the questionable integrity of the data obtained using this source (see Cesare et al. 2018), which we will discuss in more detail in the section methodology.

\section{How Analysing Google Searches can Support COVID-19 Research}

Online searching is often where people come to get answers on health and wellbeing, whether it's to find a doctor or treatment center or understand a symptom better just before a doctor's visit (Gabrilovich 2020). The pandemic accelerated the uptake of digital solutions in data collection techniques (Sogomonjan 2020). Livingstone (2020) portrayed digital technologies being harnessed to support public health responses to COVID-19 worldwide. In the short term, face-to-face survey interviews were replaced by online interviewing, and by turning to other data sources. This direction of travel had to be abruptly scaled up as it became the "new normal" for data collection and dissemination (Hantrais et al. 2020). Artificial intelligence (AI) correctly predicted the spread of COVID-19 before anybody else (Niiler 2020). AI was used extensively and in various forms in the context of COVID-19 (COE 2020). AI applications were introduced to track the pandemic in real-time, to predict accurately where the virus might appear next, and to facilitate the development of an effective vaccine (Sogomonjan 2020). AI was capable of processing vast amounts of unstructured text data to predict the number of potential new cases by area (Vaishya et al. 2020) and to forecast which types of populations would be most at risk, while also assessing, evaluating, and optimizing strategies for controlling the spread of the epidemic (Kritikos 2020).

In the past, researchers have used Google Search data (in the USA, Germany, Italy, etc.) to gauge the health impact of heatwaves, improve prediction models for influenza-like illnesses, and monitor Lyme disease incidence (Gabrilovich 2020). Google Trends makes available a dataset of search trends for researchers to study the link between symptom-related searches and the spread of COVID-19 with the aim of a better understanding of the pandemic's impact ${ }^{2}$. According to Fox (2006) and Ginsberg et al. (2009), web search queries are a uniquely valuable source of information about health trends. A set of Yahoo search queries containing the words "flu" or "influenza" were found to correlate with virologic and mortality surveillance data over multiple years (Polgreen et al. 2008). According to Bousquet et al. (2017), GT may predict the outbreak of many diseases. In Germany, correlations between the patient-based, combined symptom medication score (allergy) and GT data are stronger than those with the regionally measured pollen count data (Konig and Mosges 2014; see Marques et al. 2016). Google search interests can also be used to predict the number of asthma-related emergency department visits in the area (Ram et al. 2015, Bousquet et al. 2017). The project by Google Trends, Schema, and Axios shows how searches became

\footnotetext{
${ }^{2}$ See searchingCOVID19.com/2020.
} 
more specific as infections of COVID-19 spread across the United States (Kight 2020).

By looking at Google Trends search data related to the COVID-19 pandemic, we can discover patterns in our desire for information - waves of interest that reflect the pandemic's progression and our understanding of it. Researchers could use this dataset to study if search trends can provide an earlier and more accurate indication of the re-emergence of the virus in different parts of the country, but they also can be useful in studying the secondary health effects of the pandemic (Gabrilovich 2020). Ferguson et al. (2005) show that early detection of disease activity when followed by a rapid response, can reduce the impact of both seasonal and pandemic influenza.

This method has proven to be very useful for gaining insight into several other fields of research, such as the consequences that a pandemic and the measures associated with it have on the mental health of the population (see results). The restrictions to movements, events, and relations left serious consequences on the mental health of many individuals and family lives (Bruno 2020). In the short term, while protecting vulnerable individuals (the frail and the older adult) from the epidemic, they increase the risks of loneliness and therefore mental health issues (Hossain et al. 2020).

Previous studies have shown that public health emergencies may affect health, safety, and well-being. These effects may translate into a range of emotional reactions (such as distress or psychiatric conditions), and unhealthy behaviors (such as excessive substance use) (Pfefferbaum and North 2020). Uncertain prognoses, personal freedoms, large and growing financial losses, and conflicting messages from authorities are among the major stressors that will undoubtedly contribute to widespread emotional distress and increased risk for psychiatric illness associated with COVID-19 (Pfefferbaum and North 2020). Much of these results, although they were made predominantly in the USA, applies also to Croatia. During the first half of 2020, 37\% more misdemeanors and as much as $57 \%$ more criminal offenses were recorded in Croatia than in the same period in 2019. The Ombudsman Office of the Gender Equality in Croatia states that during the isolation due to the pandemic, it recorded an increased number of complaints of domestic and partner violence ${ }^{3}$.

Historically, economic crises have never been the preferred period for a couple to decide to have a baby (Matysiak et al. 2020). The results of Luppi et al. (2020) show that fertility plans have been negatively revised in all countries, but not in the same way. According to our method, in Croatia, the birth rate in 2021 will be just $87 \%$ of what it would be "a normal year".

The share of Internet users has increased significantly since 2009 when the first studies of this type were conducted, so the insights that can be obtained in this way are today much more reliable. By mid-2020, 58\% of the world population was estimated to be internet users, compared to almost $90 \%$ in the European Union (StatCounter 2020, Jurić 2021b). Within the EU, the same study showed that usage ranged from nearly $98 \%$ in Denmark to less than $70 \%$ in Bulgaria - in

\footnotetext{
${ }^{3}$ Gender Equality Ombudsman Croatia 2020.
} 
Croatia $(81 \%)$ (Eurostat 2020$)^{4}$. Eurostat data show that $19 \%$ of citizens in Croatia have never used the Internet, while the EU average is $11 \%$ (Eurostat 2020, Juric 2021b). According to data from the Central Bureau of Statistics (DZS) from 2019, $82 \%$ of households in Croatia have access to the Internet. The data show that when it comes to the use of the Internet, Croatia is generally comparable to the EU average. As the age increases, so does the percentage of citizens without any experience in using the Internet. That is most people who do not use the Internet come from the group over the age of 65 , as many as $62 \%$ of them. The reasons for not using the Internet in Croatia are mainly reduced to a larger share of the older, less educated, and poorer population. This is certainly a serious limiting factor for all studies of this type, and care should be taken that almost one-fifth of the population fails to be included in such sampling.

Schwab and Malleret (2020) argued that the world today is "facing a 'defining moment' as the pandemic precipitated the fusion of technologies, enabling digital technologies to extend their reach, almost uncontrolled, into every aspect of life. Building on the third digital revolution, the Fourth Industrial Revolution is distinguished from previous industrial revolutions by its 'velocity, scope, and systems impact'. This Fourth Industrial Revolution would develop exponentially rather than linearly and would 'fundamentally alter the way we live, work, and relate to one another" (Schwab, Malleret 2020). At the micro-level, families are shown to have become "digital by default" (Livingstone 2020). Among other indicators in Croatia, this is reflected in the fact that the top three searches in 2020 were related to the growth of interest in applications such as Google Classroom, Zoom, Office 365 for schools (Google Year in Search 2020).

To select the most common terms in our study to be searched, we adhered to WHO (2020a, b) and Croatia official statistics ${ }^{5}$. Infected with COVID-19 may be asymptomatic or develop symptoms such as fever, cough, fatigue, shortness of breath, or muscle aches. A review of 55,924 laboratory-confirmed cases in China showed the following typical signs and symptoms: fever ( $87.9 \%$ of cases), dry cough $(67.7 \%)$, fatigue $(38.1 \%)$, sputum production $(33.4 \%)$, shortness of breath $(18.6 \%)$, sore throat $(13.9 \%)$, headache $(13.6 \%)$, muscle pain or joint pain $(14.8 \%)$, chills $(11.4 \%)$, nausea or vomiting $(5.0 \%)$, nasal congestion $(4.8 \%)$, diarrhoea (3.7\%), haemoptysis $(0.9 \%)$ and conjunctival congestion $(0.8 \%)$ (WHO 2020). In Croatia by the onset of the epidemic, we have noticed a sharp increase in searches for several topics related to COVID-19 like "PCR + COVID", "cough + corona"; "pneumonia + corona"; "dry cough + corona"; "runny nose + coronavirus"; "muscle pain + corona", "anxiety + depression", "abortion pill", etc. Based on these findings, we checked whether the tool can be used for monitoring and predicting new COVID-19 cases and whether this method can be useful in monitoring families.

\footnotetext{
${ }^{4}$ https://ec.europa.eu/eurostat/statisticsexplained/index.php?title=Digital_economyand_society _statistics_-_households_and_individuals/hr. [Accessed 20 February 2021]

${ }^{5}$ koronavirus.hr.
} 


\section{Methodological Explanation}

The basic methodological concept of our approach is to monitor the digital trace of language searches with the Google Trends analytical tool (trends.google. com). The GT analytics application is a trend search tool that shows the popularity of a term when searching on Google, and we can see if a trend is rising or falling. GT does not provide information on the actual number of keyword searches. Instead, it standardizes search volume on a scale of 0 to 100 over the period being examined (see Jurić 2021a, b, c, d) with higher values indicating the time when the search volume was greatest, allowing for verifiable metrics ${ }^{6}$.

To standardize the data, we requested the data for the period from 20 January 2020 to 20 December 2020 (in case of predicting of new COVID-19 cases from 20 January 2020 to February 2021). When we deemed it necessary, we also collected data for longer periods (which is indicated below each figure). We then divided the keyword frequency for selected words giving us a search frequency index. We have then compared searches with official statistics to prove the significations of results (see further explanations by Wilde et al. 2020).

Further, keywords were chosen by brainstorming possible words that we believed to be predictive, specific, and common enough for use in forecasting (we used a similar method in predicting migration from Croatia; see Jurić 2021b, c). After the significance screen, we selected keywords and topics.

Table 1. Keyword and Topic Selection Criteria

\begin{tabular}{|c|c|c|c|}
\hline Symptoms & What is/How to? & Terms & Activities \\
\hline Asthma & What is coronavirus? & Influenza Complication & Coronavirus testing \\
\hline Anosmia & What is Zoom? & Cold/Flu Remedy & PCR test \\
\hline Common cold & $\begin{array}{c}\text { How to make a face } \\
\text { mask? }\end{array}$ & General Influenza Symptoms & $\begin{array}{l}\text { Application for a } \\
\text { minimum wage }\end{array}$ \\
\hline Cough & How to make hand & Term for Influenza & \\
\hline Depression & sanitizer? & $\begin{array}{c}\text { Symptoms of an Influenza } \\
\text { Complication }\end{array}$ & \\
\hline Fatigue & & Antibiotic Medication & \\
\hline Fever & & Remedies for corona & \\
\hline Headache & & General Influenza & \\
\hline Nausea & & Antiviral Medication & \\
\hline $\begin{array}{l}\text { Shortness of } \\
\text { breath }\end{array}$ & & & \\
\hline
\end{tabular}

To understand these terms, a note on the logic behind the Google Trends search algorithm is necessary. Certain delimiters, such as ", -, and + allow users to

${ }^{6}$ trends.google.com. 
change the combinations of keywords searched. A search for a single keyword will yield the search frequency index counting all searches containing that keyword, including searches that contain other words (Wilde et al. 2020).

\section{Limitations}

The study we present, as well as all other studies of this type, has important limitations that we want to highlight (see Jurić 2021b). Although previous research in this area has shown the feasibility of using digital data for demography, at the same time we highlight the problems associated with assessments and conclusions (see Zagheni et al. 2017, Zhang et al. 2020, Jurić 2021b, d). Namely, it is unquestionable that there are still significant open methodological issues and the questionable integrity of the data obtained using the sources of large data sets. Unquestionably, this model has unresolved issues related to the reproducibility of the findings and the validity of the measurements, which arise from the very characteristics of the Google Trends (GT) system used (see Jurić 2021a, b). When using this tool it should be borne in mind that each of these searches was conducted for its reason and does not answer direct questions from researchers. Thus, for example, "googling" the term "coronavirus testing" is not necessarily an implication that someone is ill or experiencing symptoms. The search queries are not exclusively submitted by users who are experiencing COVID-19 symptoms, and the correlations we observe are only meaningful across large populations. However, testing of a similar model used in the U.S. for the onset of influenza showed a high correlation between influenza symptom searches and physical reports of influenza cases (Ginsberg et al. 2009).

The fact is also a problem that GT does not provide data on which population was sampled or how it was structured (Jurić 2021d). Despite strong correlations, this system remains susceptible to false alerts. An unusual event, such as a drug recall for a popular cold or flu remedy, could cause such a false alert (Ginsberg et al. 2009). In Croatia, such an example was observed after complications with vaccination with Astra Zeneca, when interest in vaccination and vaccine types increased sharply. Although these open-ended issues pose serious challenges for making clear estimates, statistics offer a range of tools available to deal with imperfect data as well as to develop controls that take data quality into account (see "R"; see Zagheni et al. 2017). Those problems can be resolved also by triangulation. In results, we show, for example, that the increase in Google search is correlated with the increase in the number of new COVID-19 cases recorded by official statistics and that the decrease in Google search is correlated with the decrease in the number of new cases recorded by official statistics.

The Google search Index cannot estimate the exact number of searches, so with the help of this tool the exact number of new cases cannot be estimated, but the increase of the trend can be noticed very precisely (see Juric 2021a, b), which can serve as an indicator of new cases in the whole country and individual regions. We tested the method in the Croatia case by comparing the findings obtained with GT with official indicators. We show that the increase in Google search is correlated with the increase in the number of new COVID-19 cases recorded by 
official statistics and that the decrease in Google search is correlated with the decrease in the number of new cases recorded by official statistics. A particular limitation of this approach is the fact that the demographic characteristics of users cannot be determined, which plays an important role in the context of the suppression of the spread of the infection. The main advantage of this approach compared to official indicators is that it detects the phenomenon as quickly as possible and thus can serve as an early alarm. This is relevant for family life because it has been observed that the virus spreads particularly rapidly in households where more young and old people live together (Esteve et al. 2020). Namely, younger people are more often asymptomatic patients or do not feel great health problems due to infection, which is why they are often unaware that they are infected, and as such represents an extremely great danger for older members of the household. With the early detection of the spread of the virus in certain parts of the country, measures such as closing cafes, clubs, switching to online classes, etc. can be introduced quickly to take preventive action.

The demographic structure of the country plays an important role in understanding the spread of the infection. Luppi et al. (2020) in their study about the impact of COVID-19 on fertility plans suggest that the possible effect of the COVID-19 epidemic and the subsequent economic crisis cannot be merely interpreted under the same mechanisms in all European countries. Esteve et al. (2020) show the double challenge that countries such as Greece, Italy, Portugal, and Spain face: the combination of an aged population with inter-generational residence leads to high estimated death rates due to COVID-19 but also makes preventing deaths due to within-household transmission of the virus particularly challenging. Evidence shows that the risk of severe disease and mortality increases sharply with age (WHO 2020). "Therefore, the age structure of the population what proportion are young or old - and the structure of co-residency - how big are households and how old are their members - are two key factors that determine the vulnerability of countries to outbreaks of COVID-19, and how effective general and age-specific household confinement policies can be in reducing mortality after an outbreak" (Dowd et al. 2020). As the virus can be transmitted outside and within households, the effects of such measures will depend on the number of transmissions that take place outside and within the household (Esteve et al. 2020).

Preventing primary infections among the elderly is the most effective in countries with small households and little intergenerational co-residence such as France, whereas confining younger age groups can have a greater impact in countries with large and inter-generational households such as Bangladesh (Esteve et al. 2020). According to this study, Croatia can be classified as a country that shows the characteristics of the spread of infection as in southern Europe ${ }^{7}$. Whereas such studies have not been carried out in Croatia, but the lifestyle in the coastal part of Croatia is very similar to the Italian one, Italian case can suggest how to identify contexts and populations that are particularly vulnerable to agingsensitive epidemics also in the Croatian case (see Balbo et al. 2020). Those countries are characterized by a higher share of intergenerational co-residence and

\footnotetext{
${ }^{7}$ See koronavirus.hr.
} 
contacts among generations, i.e., "strong" family ties. While culture plays a role in shaping these differences, also structural factors are relevant (Balbo et al. 2020). While in "normal" times strong family ties are protective for older adults, they become a risk factor during epidemics, and aging-sensitive epidemics in particular (Balbo et al. 2020).

\section{Occurrence and Spread of Coronavirus in Croatia}

The first case of SARS-CoV-2 virus infection in Croatia was confirmed on February $25,2020^{8}$. One year later, there were 237,725 patients in Croatia. On March 11, 2020, a decision was made in Croatia to declare an epidemic of the COVID-19 disease caused by the virus ${ }^{9}$. On March 22, 2020, Croatia was hit by an earthquake measuring 5.5 on the Richter scale ${ }^{10}$, which is the strongest earthquake in Zagreb after the 1880 earthquake. It is assumed that the consequences caused by the earthquake contributed to the behaviours that contributed to the increase in the number of newly infected in the coming period ${ }^{11}$.

On April 2, more than 1,000 infections were recorded in Croatia. Due to the increase in the number of patients per 100,000 inhabitants, Croatia was placed at the end of August on the red list of a total of $13 \mathrm{EU}$ countries. The increase in mortality began at the end of August, in mid-October, the death toll rose sharply, and in December Croatia was in fourth place in Europe with a 57\% mortality surplus compared to the average of the last five years. Only Slovenia, Lithuania, and Bulgaria had higher mortality rates ${ }^{12}$. Two effects affected mortality - the premature death of many individuals who would still live without the virus, and the virus hastened the death of those nearing the end of their lives. In Croatia, COVID-19 in 2020 was the fourth leading cause of death in women and the third in men. Men had a two to three times higher risk of death from COVID in older age groups than women ${ }^{13}$.

Due to the dramatic increase, the government has announced new strict measures to combat the epidemic ${ }^{14}$. Measures that affected families were school closures, a ban on visits to nursing homes, and extended confinement of the elderly in their homes. As in other countries, there have been debates about the role that specific age groups, and particularly children, play in the transmission of the virus (see Zimmerman and Curtis 2020).

Most infected were in the north, in Međimurje County, about $10 \%{ }^{15}$. This fact is important to us because the GT also shows that the search for the mentioned terms was the largest in this region, weeks before the pandemic spread. Since midDecember, the situation has improved significantly and there are fewer active and

\footnotetext{
${ }^{8}$ koronavirus.hr.

${ }^{9}$ zdravlje.hr 2020.

${ }^{10}$ pmf.unizg.hr 2020.

${ }^{11}$ koronavirus, hr, 2020.

${ }^{12}$ ourworldindata.org, 2021.

${ }^{13}$ Čipin 2021.

${ }^{14}$ Civilna-zastita.gov.hr 2020.

${ }^{15}$ koronavirus.hr 2020.
} 
new cases every day. In the next part of the year, the situation changed, and by January 2021, with just over 1,000 registered cases per million inhabitants, Croatia recorded data like most other countries in the $\mathrm{EU}^{16}$.

In the first 400,000 people infected with coronavirus, a total of 257 patients $\operatorname{died}^{17}$. In the 2020 pandemic year, Croatia has the highest number of deaths since the civil records of deaths and excess mortality were monitored, especially during November and December $2020^{18}$. According to preliminary estimates in 2020, 56,677 people died (DZS 2021). At the end of 2020 and the beginning of 2021, there was a strong fall in the number of deaths due to pandemics and newly registered cases of infection. In the next section, we show the results obtained with Google Trends.

\section{Results}

Google Trends as a Method to Predict New COVID-19 Cases

With the outbreak of pandemic in Croatia and lockdown in March 2020 Croatian citizens are beginning to google intensively for terms related to COVID19. We checked the most COVID-19 related queries in Croatia and here we highlight the queries that showed the highest correlation with official indicators.

Figure 1. Queries Reported by GT Concerning Queries "PCR +COVID", "PCR + Test" and "Coronavirus + Testing" from May 2020 to February 2021 in Croatia

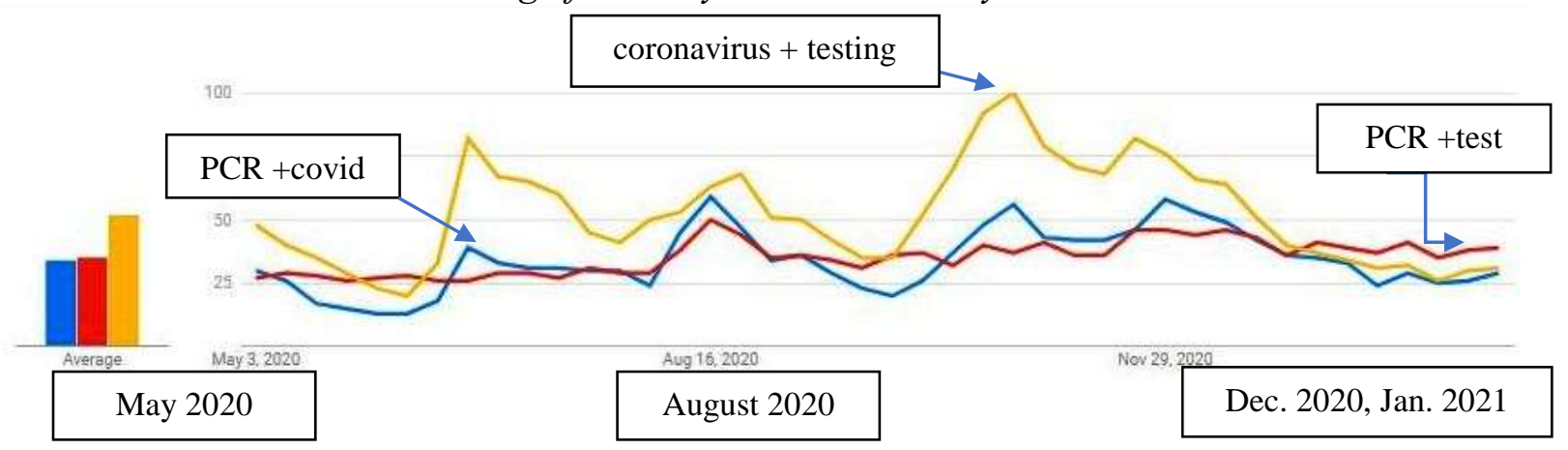

It is confirmed that the Increase in Google search queries "PCR +COVID", "PCR + test" and "coronavirus + testing" is correlated with the increase in the number of new cases (Figure 1). The decrease in Google search is correlated with the decrease in the number of new cases (see below $\mathrm{R}^{2}$ ).

\footnotetext{
${ }^{16}$ koronavirus.hr 2021.

${ }^{17}$ koronavirus.hr 2021.

${ }^{18}$ Čipin 2021.
} 
Figure 2. Queries Reported by GT Concerning Symptoms "Cough + Corona"; "Pneumonia + Corona"; "Dry Cough + Corona"; "Runny Nose + Coronavirus"; "Muscle Pain + Corona" from May 2020 to February 2021 in Croatia

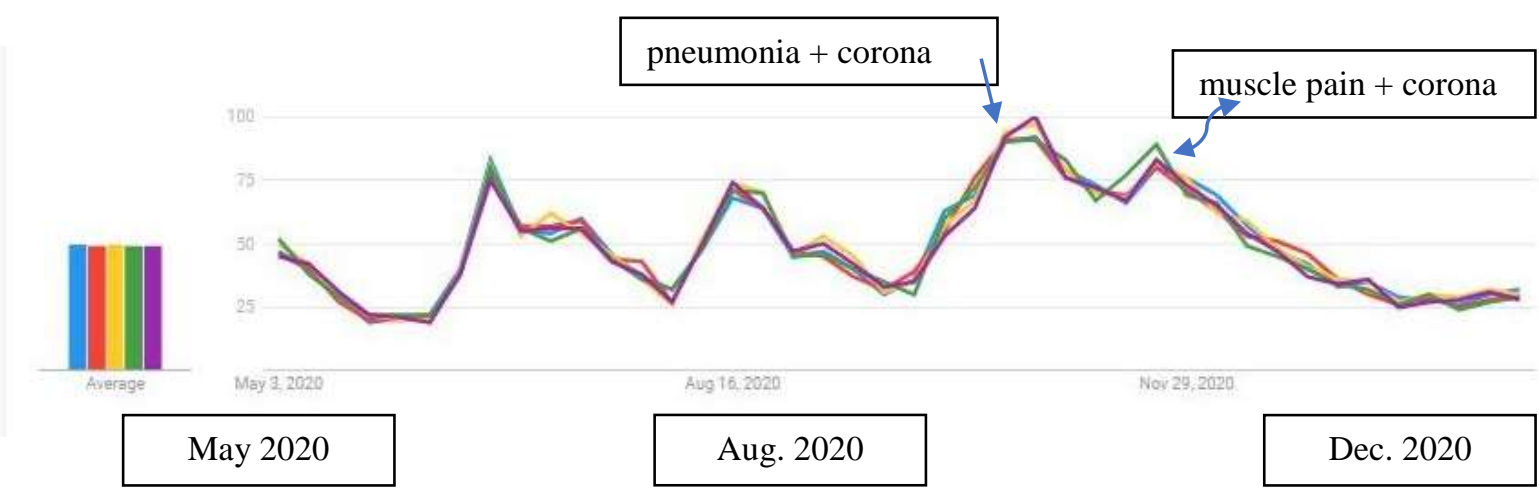

It is confirmed that the increase in Google search queries "cough + corona"; "pneumonia + corona"; "dry cough + corona"; "runny nose + coronavirus"; "muscle pain + corona" is correlated with the increase in the number of new cases (Figure 2). The decrease in Google search is correlated with the decrease in the number of new cases (see further proceedings in continuation).

Figure 3. Queries Reported by GT Concerning "Loss of Smell" and "Loss of Taste" from January 2020 to February 2021 in Croatia

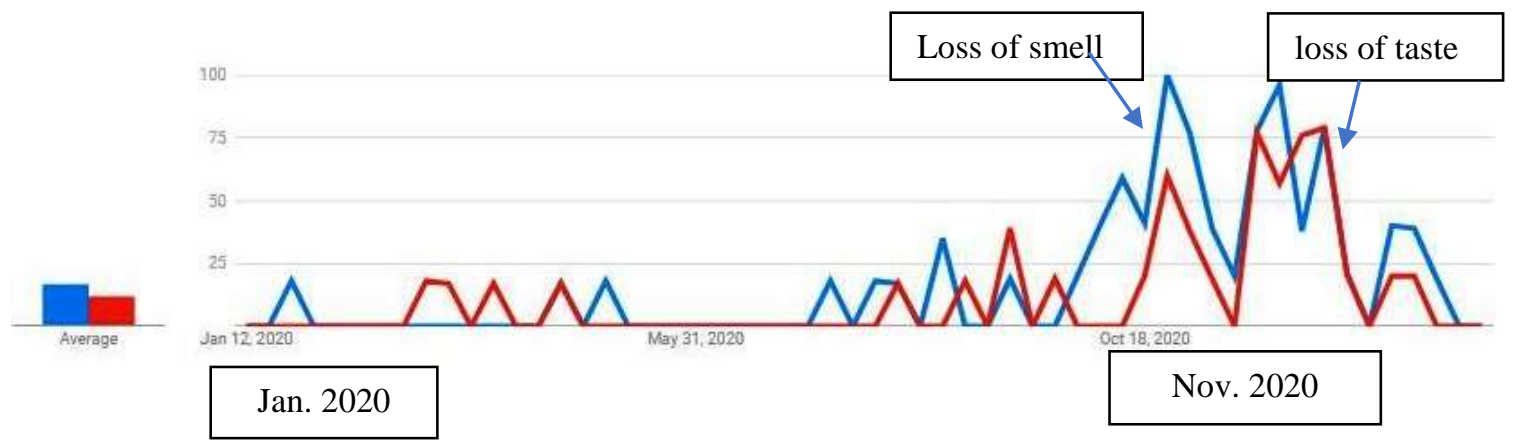

It is also confirmed that the Increase in Google search queries "loss of smell" and "loss of taste" is correlated with the increase in the number of new cases. The decrease in Google search is correlated with the decrease in the number of new cases (Figure 3). 
Figure 4. Queries Reported by GT Concerning "Neofen" (Medication) and "Sumamed" (Cro. Most Popular Antibiotic) from January 2020 to February 2021 in Croatia
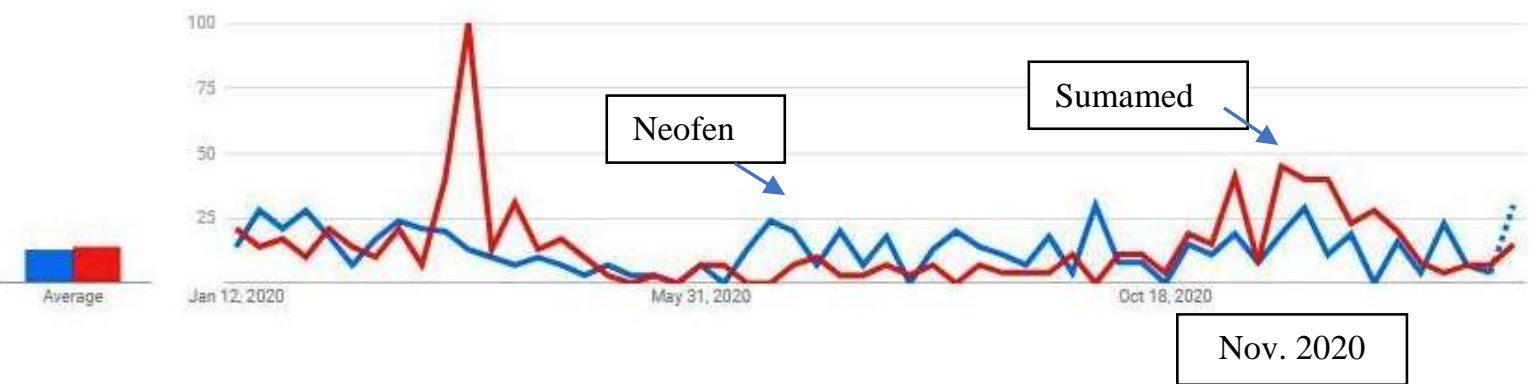

We have also researched whether the use of recommended drugs increased "Neofen" (medication for fever) and "Sumamed" (Cro. most popular antibiotic). It can be seen in Figure 4 that the demand for these drugs increased especially at the time of the pandemic outbreak and in the fall of 2020 when the largest number of new cases was recorded.

Google search interests can also be used to predict the number of COVID-19related emergency department visits in the area. The regions in which these terms were searched recorded the largest increase in the number of new cases a week later.

Figure 5. Correlation by Regions

- neofen - sumamed

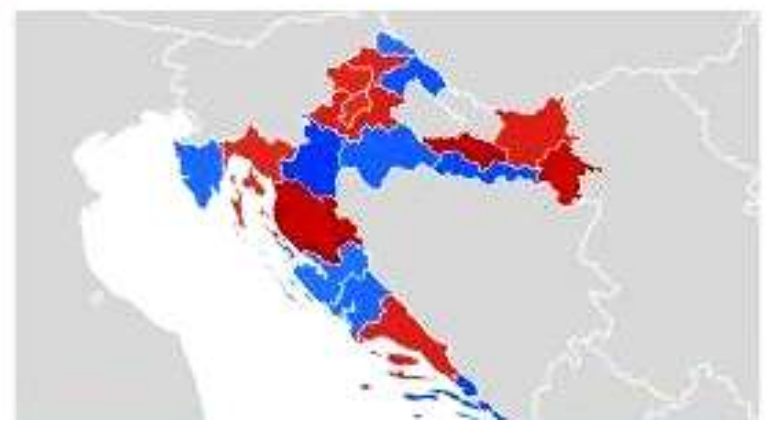

The search for these drugs correlates with a sharp increase in the number of new cases in November 2020 in the northern Croatian regions (Figure 5) ${ }^{19}$.

In further proceedings to standardize the data, we requested the data for the period from January 2020 to 20 February 2021 and divided the keyword frequency for each word (see Table 1) giving us a search frequency index. Then we have compared searches with official statistics to prove the significations of results (see HZJZ.hr). We especially focused on the so-called second wave of infection spread when cases began to grow exponentially.

${ }^{19}$ Novi list.hr 2020. 
Figure 6. Correlation between Google Search Index for Query "PCR + COVID" and the Official Number of Reported New Cases of COVID-19 Patients in Croatia by Selected Dates 2020 and 2021

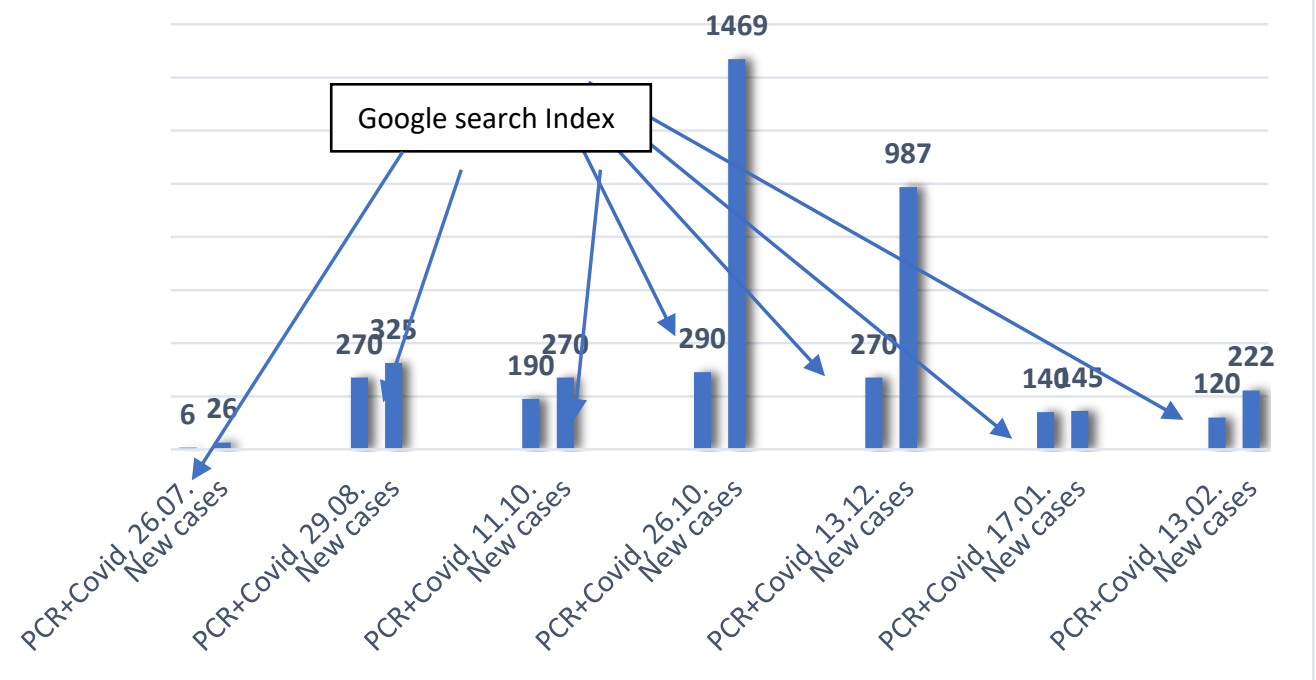

The graph in Figure 6 shows that the increase in Google search is correlated with the increase in the number of new cases and that the decrease in Google search is correlated with the decrease in the number of new cases.

Figure 7. Correlation between Google Search Index for Query "PCR +Test" and the Official Number of Reported New Cases of COVID-19 Patients in Croatia by Selected Dates 2020 and 2021

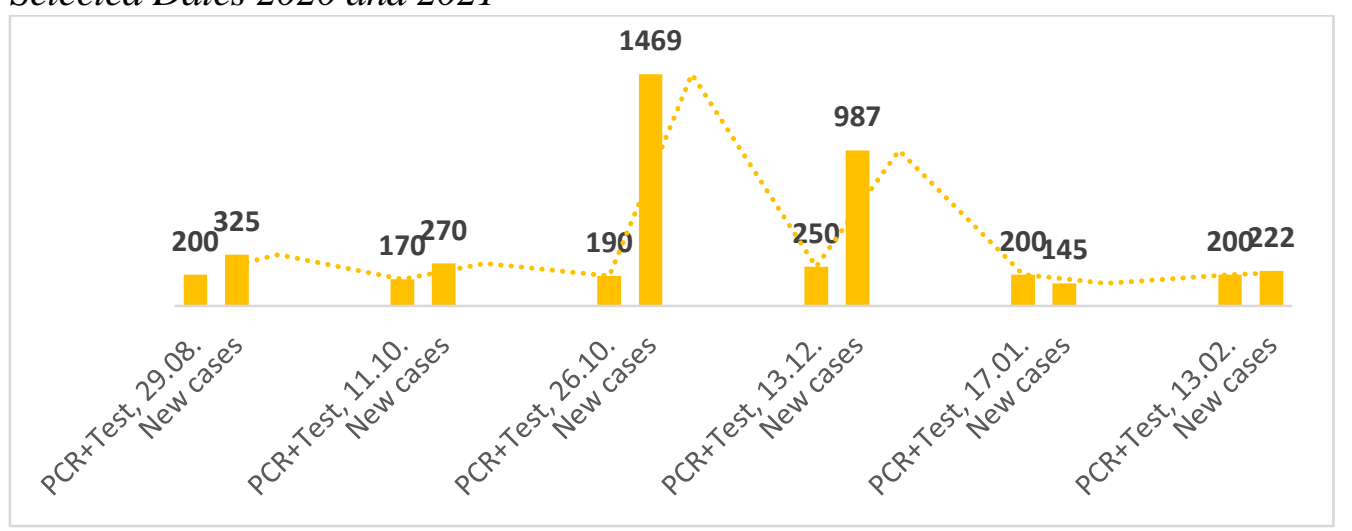

All search activities using Google for significant terms "PCR +COVID", "PCR + test", "coronavirus + test" correlate strongly with observed official cases ${ }^{20}$ of the disease (Figure 7).

${ }^{20}$ See HZJZ.hr. 
Vol. 8, No. $1 \quad$ Jurić: Google Trends as a Method to Predict New COVID-19 Cases...

In the continuation of the work we tested the model for the most common symptoms of cough, pneumonia, and muscle pain and compared the data with official data ${ }^{21}$.

Figure 8. Correlation between Google Search Index for Query "Cough +Coronavirus" and the Official Number of Reported New Cases of COVID-19 Patients in Croatia by Selected Dates 2020 and 2021

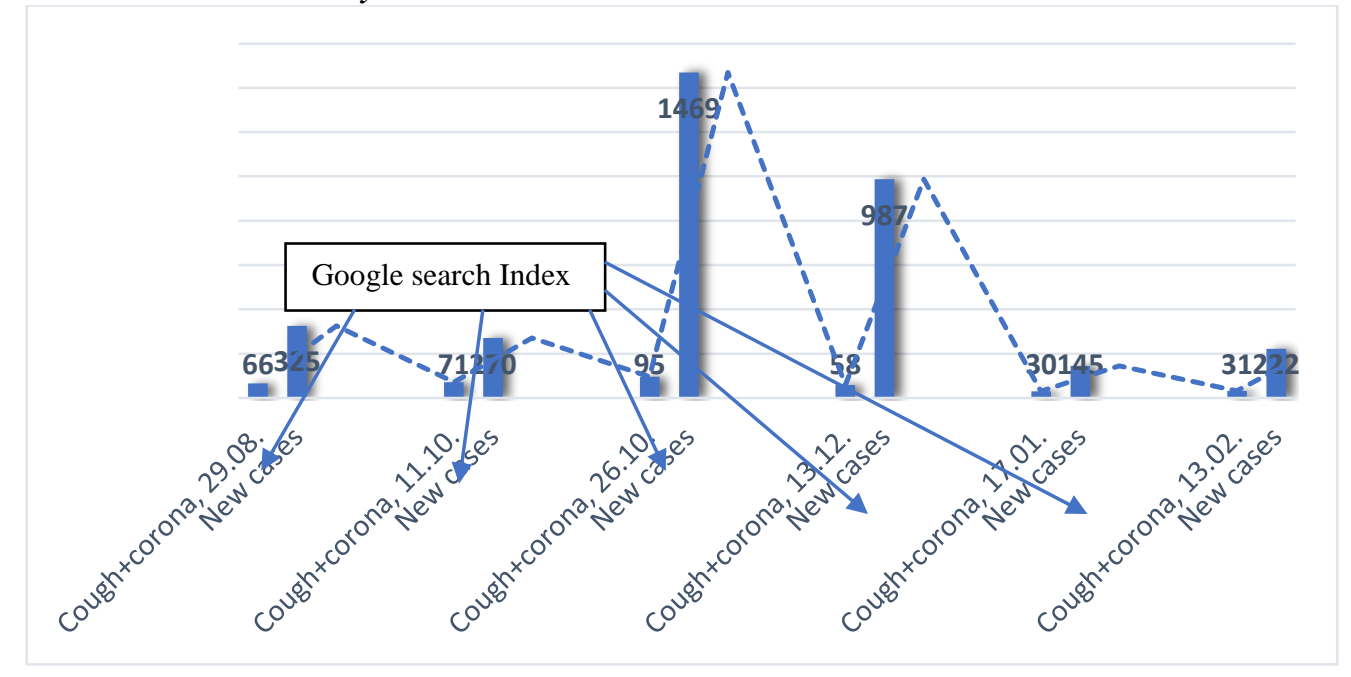

Figure 9. Correlation between Google Search Index for Query "Pneumonia +Corona" and the Official Number of Reported New Cases of COVID-19 Patients in Croatia by Selected Dates 2020 and 2021

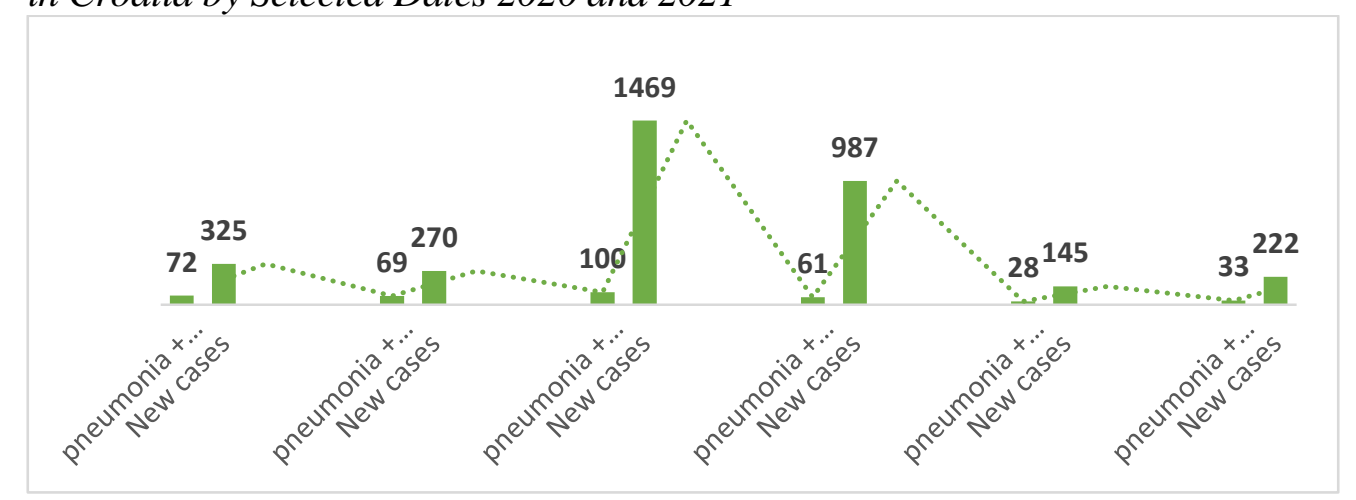

${ }^{21}$ See HZJZ.hr. 
Figure 10. Correlation between Google Search Index for Query "Muscle Pain +Corona" and the Official Number of Reported New Cases of COVID-19 Patients in Croatia by Selected Dates 2020 and 2021
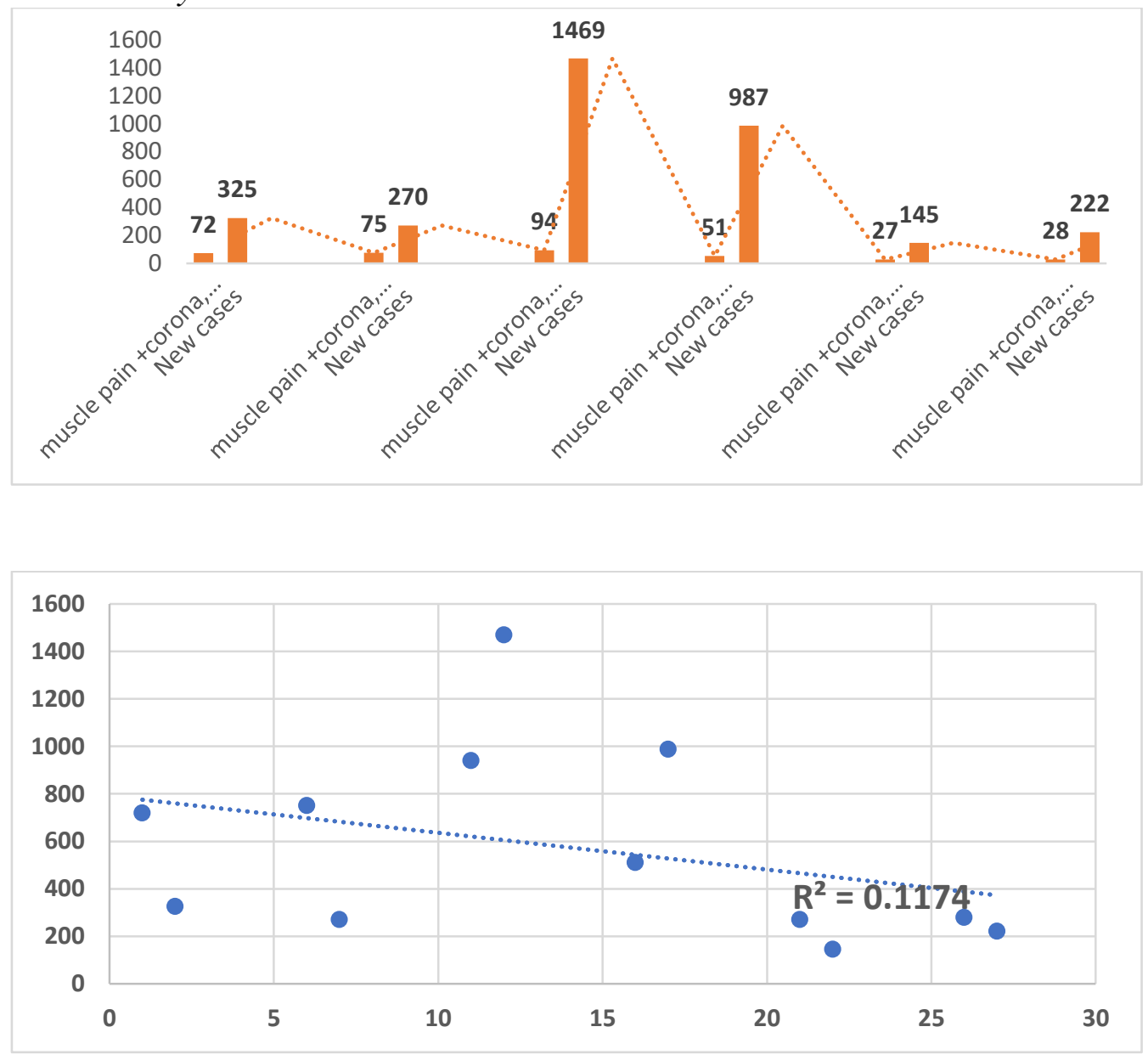

The search activities using Google for symptoms "cough + corona", "pneumonia + corona"; "muscle pain + corona" correlate with official data of new cases.

All graphs in Figures 8, 9 and 10 show that the increase in Google search is correlated with the increase in the number of new cases recorded by official statistics and that the decrease in Google search is correlated with the decrease in the number of new cases recorded by official statistics.

\section{Screening for Mental Health Problems during the Pandemic with Google Trends}

The method presented here can also identify clues that could affect mental health in some specific period.

After disasters, most people are resilient and do not succumb to psychopathology. Nevertheless, the primary concern is post-traumatic stress disorder (PTSD) arising from exposure to trauma (see Friedman 2013). Medical conditions from natural causes, such as life-threatening viral infection and earthquakes, do not meet the 
current criteria for trauma required for a diagnosis of PTSD, but other psychopathology, such as depressive and anxiety disorders, may ensue (Pfefferbaum and North 2020). It is therefore not surprising that in Croatia search queries "psychiatrist" has increased (Figure 11).

Figure 11. Search Queries "Psychiatrist" in Croatia (2017-2020)

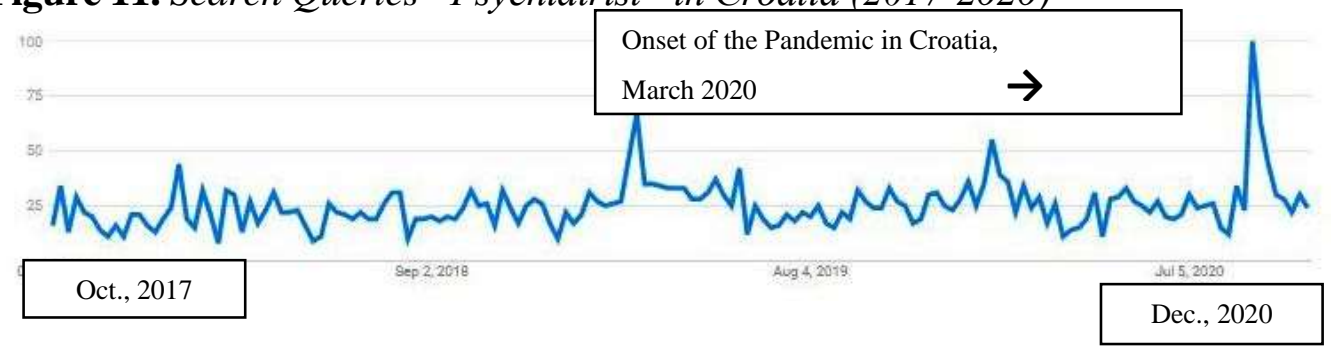

We also noticed an increase in searches for tranquilizers and sedatives like Normabel (the most popular in Croatia) (Figure 12).

Figure 12. Search Queries "Sedatives + Normabel” in Croatia (2019-2020)

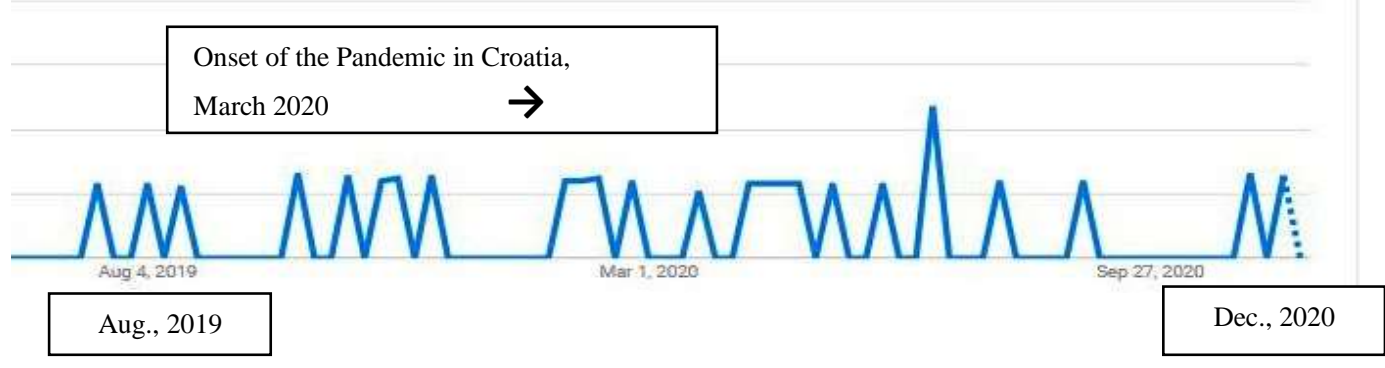

Among the global population depression and anxiety disorders have worsened during the COVID-19 pandemic. Current methods for screening these two issues rely on in-person interviews, which can be expensive, time-consuming, and blocked by social stigma and quarantines (Zhang et al. 2020, p. 1). About twothirds of the sample in a study by Jovic et al. (2020) in the USA reported using the Internet more during the pandemic, and more than $10 \%$ of participants spent over $8 \mathrm{~h}$ on the Internet daily (Jovic et al. 2020). In the case of Croatia, this depends on socio-economic factors (see introduction). Considering that traditional survey methods are time-consuming and expensive, we need timely and proactive data sources to respond to the rapidly evolving effects of health policy on the population's mental health.

Zhang et al. (2020) show that behaviours on online platforms in the USA can be used to understand personal well-being. Our insights suggest that GT has also the potential to capture clinically alarming deteriorations in the depression and anxiety profiles of users in Croatia in a non-invasive manner. Most importantly, such ubiquitous online footprints may provide useful signals of deteriorating mental health profiles (e.g., depression and anxiety) of users during COVID-19. They may capture insights into what was going on in the mind of the user through 
a non-invasive manner (Zhang et al. 2020, p. 1; see Saeb et al. 2016, Ghandeharioun et al. 2017, Wang et al. 2018).

When we look at the results of the most common entries in Croatia before and after Lockdown (Table 2), we can see that common daily topics like matches and the like have completely shifted in the direction of health concerns and other concerns.

Table 2. The Top Five Entries in Croatia before and after the Lockdown (2019 and 2020)

\begin{tabular}{|l|l|}
\hline Before lockdown (2019) & After lockdown (2020) \\
\hline 1. Results of the EU elections \#croatia & 1. Coronavirus \\
2. Strike & 2. Google Classroom; Zoom \\
3 Dinamo - Benfica & 3. Office 365 for schools \\
4 Handball Championship 2019 & 4. Zagreb earthquake \\
5 Croatia - Slovakia & 5. Kobe Bryant \\
6 Notre Dame & 6. e - Pass \\
7. Prado Museum & 7. US elections \\
8 Dinamo - Viktoria Plzen (match) & 8. Croatia State Election Commission \\
9 Love is in the Village (series) & 9. Joe Biden \\
10 Wimbledon & 10. Masons \\
\hline
\end{tabular}

Source: Google Year in Search 2020: https://trends.google.com/trends/yis/2020/HR/.

With the use of analytic tools Google Trends, we have developed functions to quantify changes in online behaviour and online searched terms during the pandemic.

Figure 13. Search Queries "Anxiety + Depression + Nervousness" in Croatia (2019-2020)

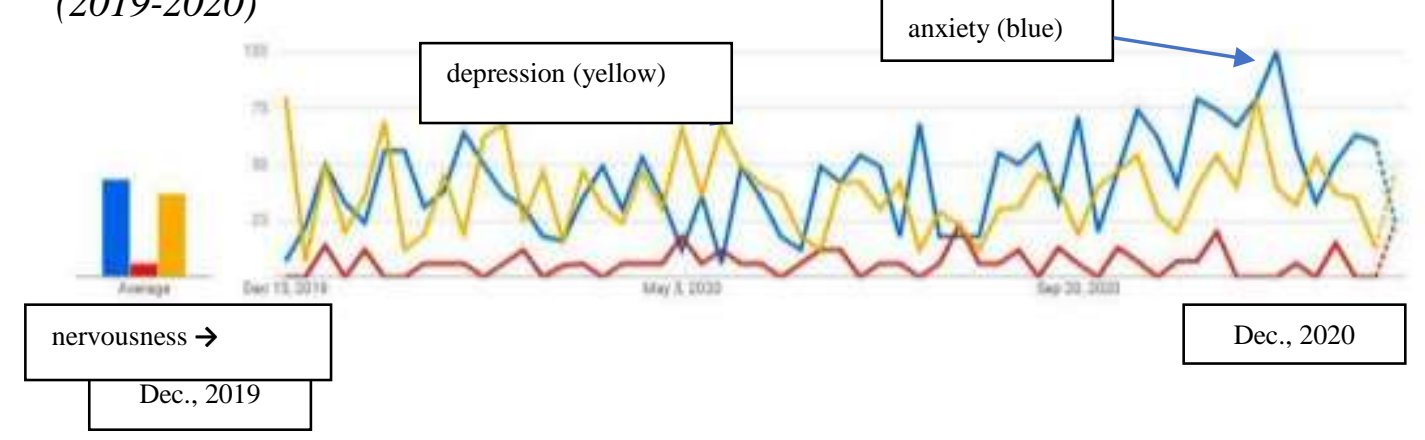

We found that collocations containing the terms "anxiety" and "sadness" keywords under the "negative emotion" dimension showed a significant increase. In this part of the study, it was particularly surprising to us how much the entries related to the phrases "suicide" and "depression" have increased in Croatia (Figure 13).

The results from Zhang et al. (2020) suggested that deteriorating depression and anxiety conditions in the USA have strong correlations with behavioral changes in Google Search use during the COVID-19 pandemic. Though further studies are required, our results for Croatia demonstrate the feasibility of using big data to establish non-invasive surveillance systems for mental health conditions that bypass many disadvantages of existing screening methods. 


\section{Domestic Violence and COVID-19 Pandemic}

Experts across the globe (USA, Italy, Germany, etc.) acknowledge the risk of an increase in family violence through and possibly beyond the COVID-19 pandemic (UN Women 2020). Preliminary estimates were that "for every 3 months the lockdown continues, an additional 15 million (...) cases of gender-based violence are expected" (UN Population Fund 2020, p. 2).

Economic insecurity and poverty-related stress appear to be the most common pathway linking pandemics and family violence. Economic stress may lead to psychological stress, poor mental health, and maladaptive coping strategies, including substance misuse and stealing money or food, which in turn are linked with an increased risk of family violence (Spiranovic et al. 2020). Social restrictions and lockdowns during the pandemic can have a detrimental impact on parents who might experience additional pressures in cases of school closures. Like the economic stress pathway, psychological stress is linked with increased family violence (Spiranovic et al. 2020). The increased violence has also grown through reductions in outside assistance and options to safely leave a violent relationship (Spiranovic et al. 2020). Restrictions and lockdowns may force women and children to remain within a violent home, and women may also be less willing or able to seek help during pandemics.

Much of this applies also to Croatia. During the first half of 2020, 37\% more misdemeanours and as much as $57 \%$ more criminal offenses were recorded in Croatia than in the same period in 2019. The Ombudsman Office of the Gender Equality states that during the isolation due to the pandemic, it recorded an increased number of complaints of domestic and partner violence. Therefore, the Office asked the Government for additional protection of women because, statistically speaking, women were a more vulnerable group in terms of labour rights, salaries and pensions, and exposure to domestic and sexual violence during the epidemic ${ }^{22}$.

In this period, we see an increase in problems in Croatia related to alcoholism, since there is an evident search for the terms such as "alcoholism", "violence and alcoholism", "how to treat alcoholism" and the like (Figure 14).

Figure 14. Search Term Related to the Phrase and Collocations "Alcoholism" in Croatia (2019-2020)

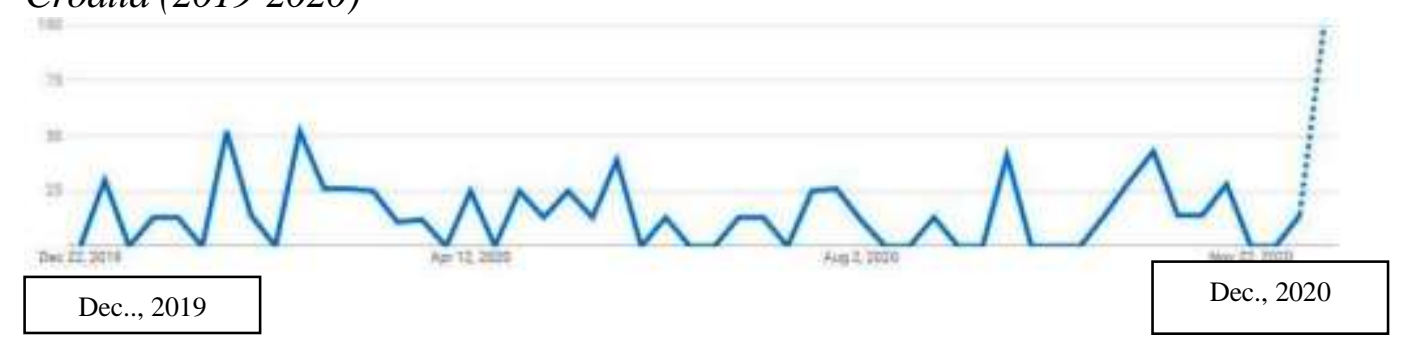

${ }^{22}$ Gender Equality Ombudsman Croatia 2020. 
An interesting finding that we have noticed is a serious indication that the number of divorces in Croatia will in 2021 growing. Besides, in 2020, the fewest marriages were concluded in Croatia since the records were kept (DZS 2021).

\section{Influences of COVID-19 Pandemic on Fertility Rate in Croatia - An Approach of Digital Demographic}

Historically, as mentioned, economic crises have never been the preferred period for a couple to decide to have a baby. The results of Luppi et al. (2020) show that fertility plans have been negatively revised in all countries, but not in the same way. In Germany and France, fertility plans changed moderately, with many people still planning or postponing their decision to have a child during 2020. In Italy, instead, the proportion of abandoners is much higher than in other countries, while comparatively, it shows a lower proportion of those deciding to postpone their plans (Luppi et al. 2020). Results suggest that different mechanisms are at work, due to the different economic, demographic, and policy pre-crisis backgrounds and post-crisis prospects. Low-fertility contexts, in particular, appear to be more at risk of a fertility loss due to the crisis (Luppi et al. 2020).

In Europe, the climate of uncertainty caused by the COVID-19 pandemic might have been stressed by the still ongoing effect of the 2008 financial crisis, especially in Southern European countries where young people and women's employment indicators and fertility rates are the lowest (Matysiak et al. 2020). Additionally, the physical distancing required by the COVID-19 containment strategy imposed also restrictions to (physical) intergenerational support and this might affect more strongly fertility plans in those countries, such as Italy and Spain, where grandparental childcare is more intensive, also due to lower availability of childcare services (Luppi et al. 2020). In countries where the previous economic and labour market situation was more positive (i.e., Germany and France) the proportion of those abandoning the fertility plans for 2020 is much lower than in the other countries; these countries, instead, show the highest proportion of people still planning a child for 2020. On the contrary, in Southern European countries, and more dramatically in Italy, people are more often abandoning - and not simply postponing - their pre-crisis fertility plans (Luppi et al. 2020).

In general, epidemics and disasters like earthquakes in Croatia (March and December 2020) manifest a common pattern as far as their impact on the population, i.e., a steep decline in birth rates followed by gradual increases and then followed by a baby boom (see Ullah et al. 2020). The USA experienced a decline in birth rates during the great economic recession in 2008, and the trend was sustained till the first half of 2009, whereas the birth rates in 2007 were the highest recorded for the prior two decades (Ullah et al. 2020). A study carried out by Pew Research Center (2009) in the USA reported that 14\% (aged 18-34) and $8 \%$ (aged 35-44) of those surveyed were still planning to postpone having a child due to the prior financial downturn (Ullah et al. 2020). Other factors such as the availability of contraception and women's educational attainment levels may also influence fertility rates (Ullah et al. 2020). Therefore, the economic recession 
caused by the COVID-19 pandemic may impose a long-term impact on the fertility rate, even after the pandemic has abated or been resolved (Ullah et al. 2020).

In this section, we examine the potential effect of the COVID-19 pandemic on future birth rates in Croatia. Keyword and topic selection criteria include search queries in Croatia during 2020: Pregnancy Intention: Ovulation Test, Pregnancy Test; Unplanned Pregnancy: Emergency Contraception, the "Morning-after" pill; Pregnancy Symptoms: Missed Period, Pregnancy Symptoms; Pregnancy Termination, Medical Abortion (see Jurić 2021a). The analytical tool Google Trends is also a useful source of data for determining, estimating, and predicting the fertility rate by the Croatian population. This method shows that monthly births in Croatia will drop sharply by approximately 13\% in the year 2021 (Jurić 2021a). These assumptions are already confirmed by the CBS (DZS) for January 2021, where according to official data, a 10\% drop in newborns can be seen (DZS 2021).

An important effect on the birth rate is played by the increase in abortions (there are no official data for now). With the GT tool, we noticed in Croatia that the demand for abortion pills increased especially at the time of the pandemic in Croatia. This trend decreased significantly as the number of COVID-19 patients fell in the summer of 2020. We also noticed an increase in searches for the term "abortus" in this period (Jurić 2021a).

In March 2020, there was a fall in demand for pregnancy and ovulation test kits in the USA (Dickson 2020), suggesting fewer people are trying to get pregnant. We also noticed this trend in Croatia based on our method.

Despite the survey in the USA, their sex lives, as well as planning for parenthood, have been substantially influenced during the COVID-19 pandemic (Micelli et al. 2020) by many reasons like worries about future economic difficulties, fear of getting infected, complications during pregnancy, shortage of healthcare workers, and disease clusters in hospitals (Ullah et al. 2020). Studies in the USA have shown that such high fatality disasters lead to a decline in births in the several months that follow such events. After several months (8-12 months) of the epidemics, a reduction in birth rates was apparent and was followed by a noticeable upward trend in the birth rates that lasted well into 20 months after the beginning of each of these epidemics (Ullah et al. 2020).

Figure 15. Search Terms Related to the Entry "Pregnancy by Weeks" in Croatia (2015-2020)

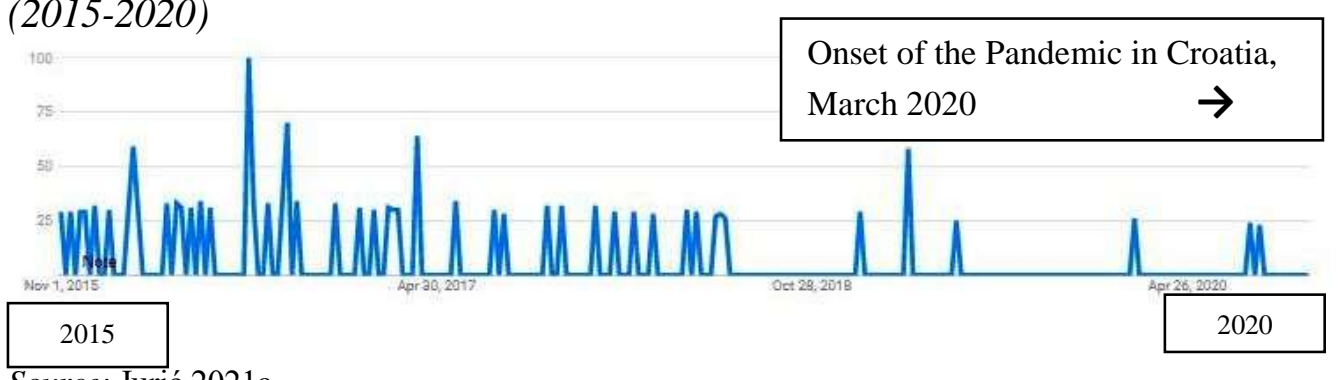


Monitoring the search for keywords related to the concepts of pregnancy by week (Figure 15) proved to be a good approach in estimating the decline in birth rates in Croatia, because the first official data for January 2021 confirmed our assumption (DZS 2021, Jurić 2021a).

All these insights show that GT has the potential to capture attitudes in the bride spectrum of family life themes. These insights can be very useful to understand and predict some behaviours in the field of public health and for monitoring families but also for predicting new COVID-19 cases in a specific area.

\section{Conclusion}

Our study reduces the gap in human behavioural data, by providing timely and accurate data on individual behaviours, attitudes and monitoring families in Croatia. The paper illustrates how Google Trends together with the official data can offer an innovative and powerful tool for rapid and continuous data collection to monitor trends in behaviours relevant for mitigation strategies of COVID-19.

The basic methodological concept of our approach is to monitor the digital trace of language searches with the Google Trends analytical tool (trends.google. com). We divided the keyword frequency for selected words giving us a search frequency index and then compared searches with official statistics to prove the significations of results. The method tested in this paper confirmed that the increase in Google search is in positive correlation with the increase in the number of new COVID-19 cases and that the decrease in Google search is correlated with the decrease in the number of new cases. Researchers could use this method to provide an earlier and more accurate indication of the re-emergence of the virus in specific parts of the country. If a region experiences an early, sharp increase in COVID-19-like-illness physician visits, it may be possible to focus additional resources on that region to identify the etiology of the outbreak, providing extra vaccine capacity or raising local media awareness as necessary. This is relevant for family life because it has been observed that the virus spreads particularly rapidly in households where more young and old people live together. In countries like Croatia which are characterized by a higher share of intergenerational co-residence and contacts among generations, this fact became a risk factor during epidemics. With the early detection of the spread of the virus in certain parts of the country, measures such as closing cafes, clubs, and switching to online classes, etc. can be introduced quickly to take preventive action.

The presented method contributes also in a way that proves the feasibility of measuring certain attitudes and behaviours in family life's during pandemics such as an increase in stress, anxiety, and domestic violence and can give reliable projection-related estimates regarding birth rates in the future. During the isolation due to the pandemic, in Croatia, we recorded an increased number of indices of domestic and partner violence. With Google Trends, we found that collocations containing the terms "anxiety" and "sadness" keywords under the "negative emotion" dimension showed a significant positive correlation. We see also an increase in problems in Croatia related to alcoholism. 
Historically, crises have never been the preferred period for a couple to decide to have a baby. An important effect on the birth rate is played by the increase in abortions. With the GT tool, we noticed in Croatia that the search for keywords related to the concepts of pregnancy by week proved to be a good approach in estimating the decline in birth rates in Croatia, because the first official data for January 2021 confirmed our assumption.

According to our method, in Croatia, the birth rate in 2021 will be just $87 \%$ of what it would be "a normal year". Monitoring the search for keywords related to the concepts of pregnancy by week proved to be a good approach in estimating the decline in birth rates in Croatia, because the first official data for January 2021 confirmed our assumption (DZS 2021).

Unquestionably, there are significant open methodological issues and the questionable integrity of the data obtained using this source. The fact is also a problem that GT does not provide data on which population was sampled or how it was structured. Although these open-ended issues pose serious challenges for making clear estimates, statistics offer a range of tools available to deal with imperfect data as well as to develop controls that take data quality into account. Many of these limitations can be overcome also by triangulation.

All these insights show that GT has the potential to capture attitudes in the bride spectrum of family life themes. These insights can be very useful to understand and predict some behaviours in the field of public health and for monitoring families but also for predicting new COVID-19 cases in a specific area, which makes it possible to take preventive actions promptly.

\section{References}

Balbo N, Billari NFC, Melegaro A (2020) The strength of family ties and vulnerability to aging-sensitive epidemics. Retrieved from: https://contexts.org/blog/structural-shocks -and-extreme-exposures/\#balbo. [Accessed 4 January 2021]

Bousquet J, O'Hehir RE, Anto J, D'Amato G, Mösges R, Hellings PW, et al. (2017) Assessment of thunderstorm-induced asthma using Google Trends. Journal of Allergy and Clinical Immunology 140(3): 891-893.

Bruno A (2020) Intergenerational relationships and mental health during the COVID-19 pandemic. World Pandemic Research Network.

Cesare N, Lee H, McCormick T, Spiro E, Zagheni E (2018) Promises and pitfalls of using digital traces for demographic research. Demography 55(5): 1979-1999.

Čipin I (2021) Demografska obiljě̌ja epidemije novog koronavirusa u Hrvatskoj (Demographic characteristics of the new coronavirus epidemic in Croatia) CLPS. https://clps.hr/demografska-obiljezja-epidemije-novog-koronavirusa-u-hrvatskoj/ [accessed 12.03.2021]

Council of Europe - COE (2020) Council of Europe and artificial intelligence. Retrieved from: https://www.coe.int/en/web/artificial-intelligence. [Accessed 4 January 2021]

Croatian Bureau of Statistics - DZS (2021) Natural change in population. DZS.

Dickson EJ (2020) With couples rethinking children, we might see the opposite of a COVID-19 baby boom. RollingStone. Retrieved from: https://www.rollingstone.com/ culture/culture-features/covid-19-fertility-birthrate-baby-boom-pregnancy-1003104/. [Accessed 18 June 2020] 
Dowd JB, Andriano L, Brazel DM, Rotondi V, Block P, Liu Y, et al. (2020) Demographic science aids in understanding the spread and fatality rates of COVID-19. PNAS 117(18): 9696-9698.

Esteve A, Permanyer I, Boertien D, Vaupel J (2020) National age and co-residence patterns shape COVID-19 vulnerability. medRxiv preprint.

Ferguson NM, Cummings DAT, Cauchemez S, Fraser Ch, Riley S, Meeyai A, et al. (2005) Strategies for containing an emerging influenza pandemic in Southeast Asia. Nature 437(7056): 209-214.

Fox S (2006) Online Health Search 2006. Pew Internet \& American Life Project.

Gabrilovich E (2020) Using symptoms search trends to inform COVID-19 research. Retrieved from: https://blog.google/technology/health/using-symptoms-search-trends -inform-COVID-19-research. [Accessed 4 January 2021]

Gender Equality Ombudsman Croatia - Prs.hr (2020) Retrieved from: https://prs.hr/cms/ post/458. [Accessed 5 January 2021]

Ghandeharioun A, Fedor S, Sangermano L, Ionescu D, Alpert J, Dale C, et al. (2017) Objective assessment of depressive symptoms with machine learning and wearable sensors data. IEEE Xplore.

Ginsberg J, Mohebbi M, Patel R (2009) Detecting influenza epidemics using search engine query data. Nature 457(Feb): 1012-1014.

Google Year in Search (2020) Retrieved from: https://trends.google.com/trends/yis/2020/ HR/. [Accessed 20 December 2020]

Hantrais L, Lenihan TA (2021) Social and security dimensions of evidence-based policy in a digital age. Contemporary Social Science (forthcoming).

Hantrais L, Allin P, Kritikos M, Sogomonjan Prathivadi M (2020) COVID-19 and the digital revolution. Contemporary Social Science: Journal of the Academy of Social Sciences 16(2): 256-270.

Hossain Md M, Sultana A, Purohit N (2020) Mental health outcomes of quarantine and isolation for infection prevention: a systematic umbrella review of the global evidence. Epidemiology \& Health 42(Jun): e2020038.

HZJZ.hr (2020) Koronavirus - Najnoviji podatci (Coronavirus - Latest data). Retrieved from:https://www.hzjz.hr/priopcenja-mediji/koronavirus-najnoviji-podatci/. [Accessed 20 January 2021]

Jovic J, Pantovic-Stefanovic M, Mitkovic-Voncina M., Dunjic-Kostic B., Mihajlovic G, Milovanovic S, et al. (2020) Internet use during coronavirus disease of 2019 pandemic: Psychiatric history and sociodemographics as predictors. Indian Journal of Psychiatry 62(9): 383-390.

Jurić T (2021a) The deep demographic aging of Croatia - Predicting of natural population change with digital demography tools. In I Barković Bojanić, A Erceg (eds.), Strategic Approach to Aging Population: Experiences and Challenges. Croatia: Faculty of Economics in Osijek, J.J. Strossmayer University of Osijek (in publishing).

Jurić T (2021b) Forecasting migration and integration trends by using digital demography and big data - The case study of Austria and Germany. Comparative Southeast European Studies (forthcoming).

Jurić T (2021c) Medical brain drain from Western Balkan and Croatia to Germany and Austria - An approach to the digital demography (forthcoming).

Jurić T (2021 d) Facebook i Google kao empirijska osnova za razvoj metode digitalnog praćenja vanjskih migracija hrvatskih građana (Facebook and Google as an empirical basis for the development of a method for monitoring external migration of Croatian citizens). Ekonomski Pregled (forthcoming). Kight SW (2020, April 27) Searching for answers in a pandemic. Axios Media. 
Konig V, Mosges RA (2014) Model for the determination of pollen count using Google search queries for patients suffering from allergic rhinitis. Journal of Allergy 2014(3): 381983.

Kritikos M (2020) At a glance: what if we could fight coronavirus with artificial intelligence? Scientific Foresight Unit, European Parliamentary Research Service.

Livingstone S (2020) Digital by default: the new normal of family life under COVID-19. Retrieved from: https://blogs.lse.ac.uk/parenting4digitalfuture/2020/05/13/digital-bydefault/. [Accessed 20 January 2021]

Luppi F, Arpino B, Rosina A (2020) The impact of COVID-19 on fertility plans in Italy, Germany, France, Spain and UK. Demographic Research 43(47): 1399-1412.

Marques GJ, Carreiro Martins P, Belo J, Alves C, Paiva M, Caeiro E (2016) Pollen counts influence web searches for asthma and rhinitis. Journal of Investigational Allergology \& Clinical Immunology 26(3): 192-194.

Matysiak A, Sobotka T, Vignoli D (2020) The great recession and fertility in Europe: a sub-national analysis. European Journal of Population 37(1): 29-64.

Micelli E, Cito G, Cocci A, Polloni G, Russo GI, Minervini A (2020) Desire for parenthood at the time of COVID-19 pandemic: an insight into the Italian situation. Journal of Psychosomatic Obstetrics \& Gynecology 41(3): 183-190.

Niiler E (2020) An AI epidemiologist sent the first warnings of the Wuhan virus. Retrieved from: https://www.wired.com/story/ai-epidemiologist-wuhan-public-health-warning s/. [Accessed 29 January 2020]

Perrotta D, Grow A, Rampazzo F, Cimentada J, Del Fava E, Gil-Clavel S, et al. (2020) Behaviors and attitudes in response to the COVID-19 pandemic: insights from a cross-national Facebook survey. MedRxiv Preprint.

Pfefferbaum B, North CS (2020) Mental health and the COVID-19 pandemic. The New England Journal of Medicine 383(6): 510-512.

Polgreen PM, Chen Y, Pennock DM, Forrest ND (2008) Using internet searches for influenza surveillance. Clinical Infectious Diseases 47(11): 1443-1448.

Ram S, Zhang W, Williams M, Pengetnze Y (2015) Predicting asthma-related emergency department visits using big data. IEEE Journal of Biomedical and Health Informatics 19(4): 1216-1223.

Saeb S, Lattie EG, Schueller SM, Kording KP, Mohr DC (2016) The relationship between mobile phone location sensor data and depressive symptom severity. PeerJ 4(Sep): e2537.

Schwab M, Malleret T (2020) COVID-19: the great reset. Geneva: World Economic Forum.

Sogomonjan M (2020) Challenges and opportunities for e-mental health policy: an Estonian case study. Contemporary Social Science 16(2): 185-198.

Spiranovic C, Hudson N, Winter R, Stanford S, Norris K, Bartkowiak-Theron I, et al. (2020) Navigating risk and protective factors for family violence during and after the COVID-19 'perfect storm'. Current Issues in Criminal Justice 33(2): 1-14.

SSOC (2020a) Seismological service of Croatia. Zagreb, Croatia: University of Zagreb.

SSOC (2020b) Seismological service of Croatia. Zagreb, Croatia: University of Zagreb.

StatCounter (2020) Internet world stats. Retrieved from: https://www.internetworldstats. $\mathrm{com} / \mathrm{stats} . \mathrm{htm}$. [Accessed 20 January 2021]

Friedman MJ (2013) Trauma- and stressor-related disorders - TSRD. In Diagnostic and Statistical Manual of Mental Disorders, 265-290. 5th Edition. Arlington, VA: American Psychiatric Association. 
Ullah A, Moin AT, Araf Z, Bhuiyan AR, Griffiths MD, Gozal D (2020) Potential effects of the COVID-19 pandemic on future birth rate. Frontiers in Public Health 8(Dec): 578438.

UN Population Fund (2020) World migration report 2020. Geneva: IOM Publications.

UN Women (2020) Annual report 2019-2020. Retrieved from: https://www.unwomen. org/en/digital-library/publications/2020/06/annual-report-2019-2020. [Accessed 20 February 2021]

Vaishya R, Javaid M, Khan IH, Haleem A (2020) Artificial Intelligence (AI) applications for COVID-19 pandemic. Diabetes \& Metabolic Syndrome: Clinical Research \& Reviews 14(4): 337-339.

Wang R, Wang W, daSilva A, Huckins JF, Kelley WM, Heatherton TF (2018) Tracking depression dynamics in college students using mobile phone and wearable sensing. Proceedings of the ACM on Interactive Mobile Wearable and Ubiquitous Technologies 2(1): 1-26.

WHO (2020) Report of the WHO-China joint mission on coronavirus disease 2019 (COVID-19). WHO. Retrieved from: https://www.who.int/docs/default-source/corona viruse/who-china-joint-mission-on-COVID-19-final-report.pdf. [Accessed 10 January 2021]

Wilde J, Chen W, Lohmann S (2020) COVID-19 and the future of US fertility: what can we learn from Google? IZA Discussion Papers. Retrieved from: https://www.econstor. eu/bitstream/10419/227303/1/dp13776.pdf. [Accessed 10 January 2021]

Zagheni E, Weber I, Gummadi K (2017) Leveraging Facebook's advertising platform to monitor stocks of migrants. Population and Development Review 43(4): 721-734.

Zhang B, Zaman A, Silenzio V, Kautz H, Ehsan H (2020) The relationships of deteriorating depression and anxiety with longitudinal behavioral changes in Google and YouTube use during COVID-19: observational study. JMIR Mental Health 7(11): e24012.

Zimmerman P, Curtis N (2020) Coronavirus infections in children including COVID-19: an overview of the epidemiology, clinical features, diagnosis, treatment and prevention options in children. The Pediatric Infectious Disease Journal 39(5): 355368 . 
